\section{L-655,708 DOES NOT PREVENT ISOFLURANE-INDUCED MEMORY DEFICITS IN OLD MICE}

Abstract

Background: General anesthesia and increasing age are two main risk factors for postoperative cognitive dysfunction (POCD). Effective agents for the prevention or treatment of POCD are urgently needed. L-655,708, an inverse agonist of a5 subunit-containing $\gamma$-aminobutyric acid subtype $A$ (a5GABA ) receptors, can prevent anesthesia-induced memory deficits in young animals. However, there is a lack of evidence of its efficacy in old animals. Methodology: Young (3- to 5-month-old) and old (18- to 20-month-old) mice were given an inhalation of $1.33 \%$ isoflurane for 1 hour and their associative memory was evaluated 24 hours after anesthesia using fearconditioning tests (FCTs). To evaluate the effect of L-655,708, mice received intraperitoneal injections of L-655,708 $(0.7 \mathrm{mg} / \mathrm{kg})$ or vehicle 30 minutes before anesthesia. Results: Old mice exhibited impaired memory and lower hippocampal a5GABA levels than young mice under physiological conditions. Pre-injections of L-655,708 significantly alleviated isoflurane-induced memory decline in young mice, but not in old mice. Conclusions: $\mathrm{L}-655,708$ is not as effective for the prevention of POCD in old mice as it is in young mice. The use of inverse agonists of $\mathrm{a}_{5 \mathrm{GABA}}$ in preventing POCD in old patients should be carefully considered.

Keywords - POCD • Old age • GABA • Inverse agonist • L-655,708
Teng Gao'"\#,

Yue Liu2",

Zifang Zhao ${ }^{2}$

Yuan Luo ${ }^{3}$,

Lifang Wang ${ }^{2}$

Yongan Wang ${ }^{3 *}$

Yiqing Yin ${ }^{2 *}$

'Department of Anesthesiology, Beijing Shijitan Hospital, Capital Medical University, Beijing, 100038, China

2Department of Anesthesiology, China-Japan Friendship Hospital, Beijing, 100029, China

State Key Laboratory of Toxicology and Medical Countermeasures, Academy of Military Medical Sciences, Beijing, 100850, China

\# Equal contributors

Received 29 January 2019

accepted 21 June 2019

\section{Introduction}

Life expectancy rises across the globe, and more and more elderly patients are undergoing surgery and receiving anesthesia. The incidence of postoperative cognitive dysfunction (POCD), which refers to a decline in learning and memory after surgery [1], is much higher in aged patients than in young patients $[2,3]$. POCD not only decreases the life quality of patients, but also imposes a serious burden on healthcare [4], and there is to date no effective therapy for POCD. Thus, effective agents for the prevention or treatment of POCD are urgently needed.

The $\gamma$-aminobutyric acid subtype $A\left(G_{A B A}\right)$ receptor is the main target for most anesthetics [5]. $G_{A B A}$ receptors are chloride-selective ion channels composed of multiple subunits (a1-6, $\beta 1-3, \gamma 1-3, \delta, \varepsilon, \theta, \pi, \rho 1-3$ ) [6], and most $G A B A_{A}$ receptors consist of two a subunits, two $\beta$ subunits and one $\gamma$ subunit [6]. In particular, the a5 subunit-containing $\left.\operatorname{GABA}_{\mathrm{A}}\left(\mathrm{a}_{5 \mathrm{GABA}}\right)_{\mathrm{A}}\right)$ receptor, which preferentially localizes in the hippocampus [7], plays an important role in memory and learning. The genetically deletion or reduction of a5GABA can improve cognitive function under physiological conditions [8-10]. Furthermore, the activation of a5GABA contributes to the amnestic effect of anesthetics and anesthesia-induced memory decline [11-13]. Therefore, inhibiting the ${ }^{5} 5 \mathrm{GABA}$, receptors has become a potential strategy to prevent or to treat POCD.

$\mathrm{L}-655,708$ is an inverse agonist of a5GABA $A_{A^{\prime}}$ acts as a negative allosteric modulator (NAM) of a5GABA $A_{A}$ receptors [14]. Studies have suggested that $\mathrm{L}-655,708$ not only enhances cognition under normal conditions [15], but also prevents anesthesia-induced memory deficits in rodents $[13,16,17]$. Most of these experiments were done in young rodents, and the evidence about the effect of L-655,708 in old animals remains lacking. Since the elderly patients are more susceptible to POCD than young patients, in current study, we sought to evaluate the efficacy of $L-655,708$ in preventing POCD in old animals.

\section{Materials and Methods}

\section{Animals}

All animal procedures were approved by the Animal Experimental Ethics Committee of the China-Japan Friendship Hospital (Beijing, China). 3- to 5-month-old (young) and 18to 20-month-old (old) male C57/BL6 mice, which correspond to 20- to 30-year-old and 60- to 70-year-old human respectively [18], were purchased from Vital River Laboratories Animal Technology Co. Ltd. (Beijing, China; Permit Number: SCXK (JING) 2012-0001). The animals were housed in standard cages under controlled laboratory conditions (temperature of $22 \pm 2{ }^{\circ} \mathrm{C}, 12$-hr light/12-hr dark cycle) with free access to food and water.

\section{Anesthesia}

The anesthesia procedure was performed as previously described [16, 19]. Briefly, the anesthetic chamber was pre-flushed with $30 \%$ oxygen in air, with (the isoflurane inhalation group) or without (the control group) 1.33\% isoflurane. The concentration of isoflurane, oxygen, and carbon dioxide in the chamber were continuously monitored by gas analyzer (Datex-Ohmeda). When the gas concentration was stable, the mice were placed in the chamber for 1 hour. After anesthesia, mice were returned to their home cage. 


\section{Fear-conditioning tests}

All mice were allowed to adapt to the fearconditioning chamber (Med Associates Inc.) for 7 days (10 mins each day) before the behavioral tests. At 24 hours after isoflurane anesthesia, the mice were allowed to explore the fearconditioning chamber for 3 minutes, followed by six rounds of fear-conditioning training. One round of training consisted of a $2 \mathrm{~Hz}$ pulsating tone $(80 \mathrm{~dB}, 3600 \mathrm{~Hz})$ presented for 30 seconds, followed immediately by a mild foot shock ( 0.7 $\mathrm{mA}$ for 0.5 seconds). Contextual tests were conducted 30 minutes after training, and tonecued tests were conducted 90 minutes after training. For the contextual test, the mice were placed in the same chamber without tone or shock for 3 minutes and their freezing behavior was scored. For the tone-cued test, the mice were placed in an altered chamber with a tone stimulus and their freezing behavior was scored for 6 minutes. The freezing behavior is monitored and analyzed by the observer software (TSE system), and the freezing score is calculated as the ratio of freezing time to total monitoring time.

\section{Western blot}

After the tone-cued test was conducted, the mice were euthanized and their hippocampus tissue was isolated. Western blotting was performed as previously described [20]. The primary antibodies used were a5GABA (ab10098; Abcam) and GAPDH (5174; Cell Signaling Technology). Western blots were quantified densitometrically using Image ProPlus software (Media Cybernetics), and the intensity values of $\mathrm{a}_{5 \mathrm{GABA}}$, were calculated relative to GAPDH.

\section{L-655,708 treatment}

Mice in the L-655,708 group and the vehicle group received intraperitoneal injections of 0.7 mg/kg L-655,708 (130477-52-0; Sigma-Aldrich) or $10 \%$ dimethyl sulfoxide (DMSO), respectively. At 30 minutes after the injection of L-655,708 or DMSO, the mice were anesthetized with $1.33 \%$ isoflurane for 1 hour, and behavioral tests were conducted 24 hours later, as mentioned earlier. The groups and experimental timelines are depicted in Figure 1.

\section{Statistical analysis}

Quantitative results are expressed as means \pm SD. The behavioral data were initially tested for normality using KolmogorovSmirnov test with Dallal-Wilkinson-Lillie for corrected $P$ value, and then tested for equal variances using Bartlett's test. For normally distributed variables, a one-way ANOVA plus a posthoc analysis (Bonferroni test) was used and for variables not passing a normality or equal variance test, a Kruskal-Wallis test plus a posthoc analysis (Dunn's multiple comparison test) was used. The quantitative results of the western blots were statistically evaluated using unpaired Student's $t$ tests. All statistical analyses were performed using GraphPad Prism 6.0 software. A P-value $<0.05$ was considered statistically significant.

\section{Results}

Old mice exhibited poorer memory than young mice both under physiological conditions and after isoflurane inhalation.

To investigate the influence of anesthesia on cognitive function at different ages, we first measured the baseline memory of old and young mice. The FCT is one of the most commonly used behavioral tests to examine cognitive deficits induced by anesthesia, it assesses the hippocampi-dependent (contextrelated) and hippocampi-independent (tonerelated) memory [21, 22]. We found that under physiological conditions, the freezing scores of old mice was notably lower than that of young mice in contextual tests, but not in tone-cued tests (Fig 2, Supplemental Table), indicating

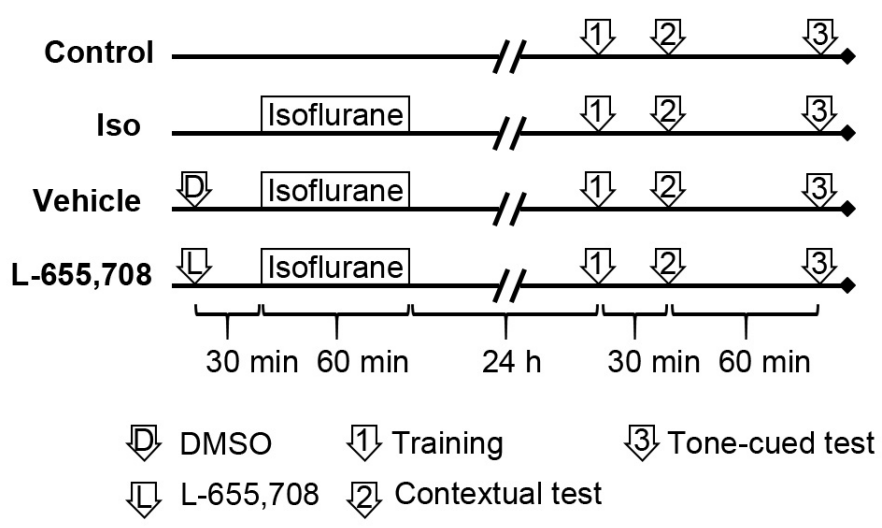

Figure 1. Groups and experimental timelines.
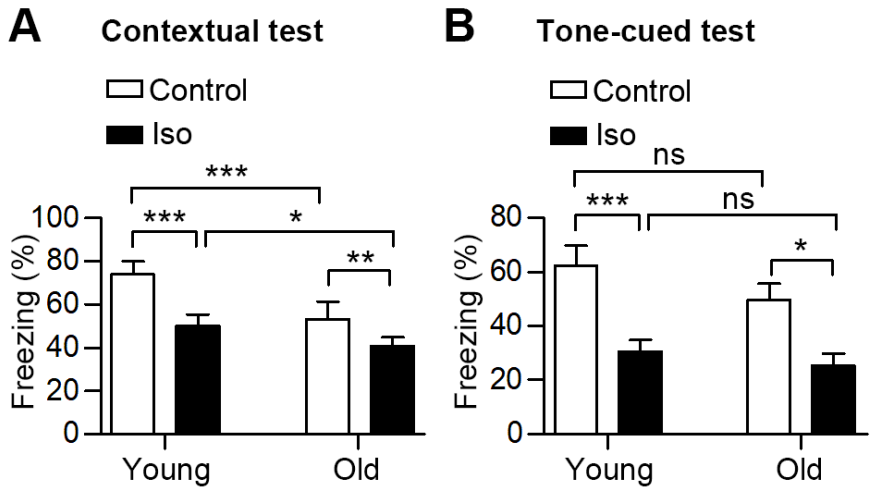

Figure 2. Freezing scores to the context $(A)$ and to the audible cue $(B)$ of the young and old mice under normal conditions and after anesthesia. $n=10$ in the groups of young mice; $n=6$ in the groups of old mice. All values show means $\pm \mathrm{SD}$. ${ }^{*}, \mathrm{P}<0.05$; ${ }^{* *}, \mathrm{P}<0.01$; ${ }^{* *}, \mathrm{P}<0.001$; ns, not significant. P-values were obtained using one-way ANOVA plus Bonferroni posthoc tests in A and Kruskal-Wallis test plus Dunn's multiple comparison test in B. Iso, Isoflurane. 
impaired hippocampi-dependent memory in the old mice. We further gave young and old mice an inhalation of $1.33 \%$ isoflurane for 1 hour and evaluated their memory 24 hours after anesthesia using FCTs. After isoflurane inhalation, freezing times in both the contextual test and the tone-cued test were significantly decreased in young mice (Fig 2, Supplemental Table). Consistently, the freezing times of old mice were also markedly decreased after anesthesia (Fig 2, Supplemental Table). The difference of the freezing scores after anesthesia between the old and young mice was statistically significant in the contextual tests, while the difference was not remarkable in the tone-cued tests. Taken together, we found that the hippocampi-dependent memory of old mice was worse than that of the young mice under normal conditions and after anesthesia.

\section{Expression of hippocampal} a5GABAA decreased with age.

The $a 5 G A B A_{A}$ receptors are mainly located in the hippocampus and play a critical role in hippocampi-dependent memory $[7,8]$. A previous study suggested that the activity and expression of a5GABA is increased by anesthetics and contributes to POCD [13]. We therefore wondered whether the expression of a5GABA increases in old mice, and whether it would be even higher after isoflurane anesthesia. However, western blotting showed that the expression of a5GABA $A_{A}$ decreased in the hippocampus of old mice compared with young mice under normal conditions (Fig $3 \mathrm{~A}$ ). Furthermore, a 1-hour exposure to isoflurane did not significantly increase the protein expression of a5GABA $A_{A}$ in the hippocampus of both young (Fig $3 \mathrm{~B}$ ) and old mice (Fig $3 \mathrm{C}$ ). These data suggest that aging causes a decrease in hippocampal a5GABA ${ }_{A}$ expression, but that a 1-hour isoflurane inhalation has no significant effect on the protein expression of a5GABA in the mouse hippocampus.

\section{L-655,708 did not improve} isoflurane-induced memory deficits in old mice.

Studies have shown that the inverse a5GABA agonist $L-655,708$ can improve cognitive
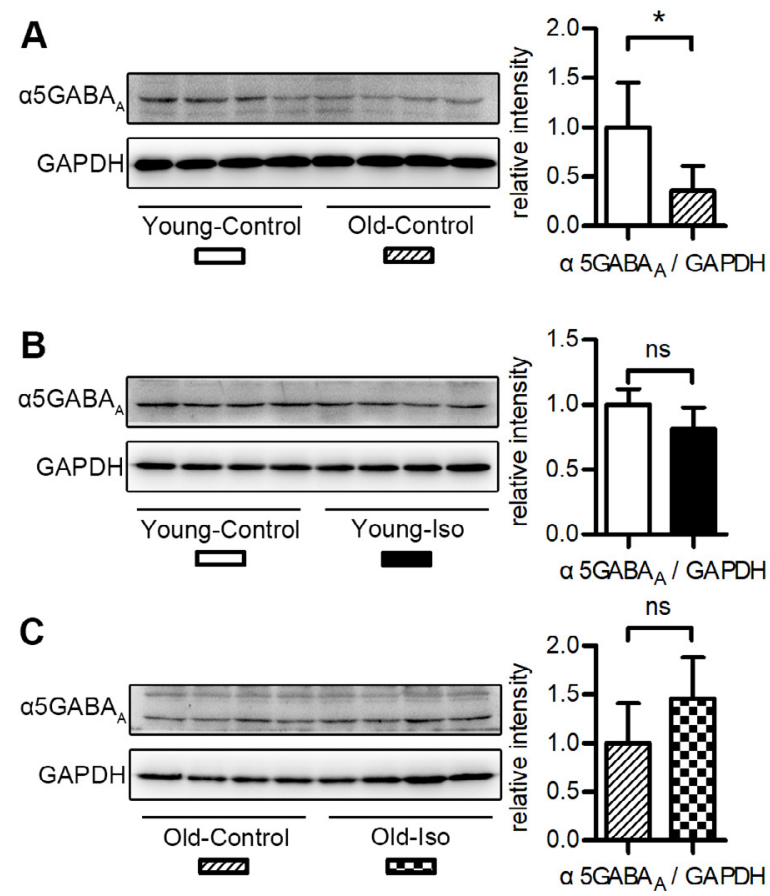

Figure 3. Hippocampal a5GABAA expression in the young and old mice. Quantification of western blots is provided. $n=4$ per group. All values show means $\pm S D$. ${ }^{*}, P<0.05 ; n s$, not significant. $P$-values were obtained using unpaired Student's t tests. Iso, isoflurane.

A Contextual test

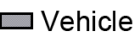

L-655,708

ns

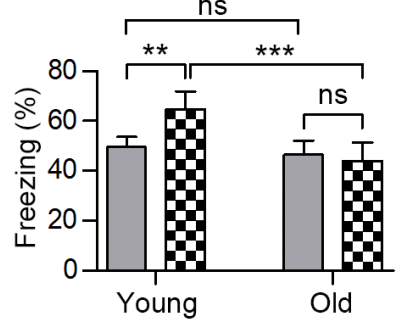

B Tone-cued test

$\square$ Vehicle

모 L-655,708

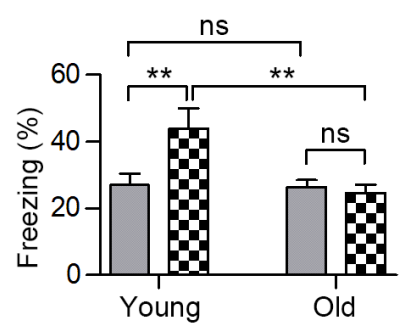

Figure 4. Freezing scores to the context $(A)$ and to the audible cue $(B)$ of the young and old mice pre-injected with $L-655,708$ or vehicle (DMSO). $n=10$ in the groups of young mice; $n=6$ in the groups of old mice. All values show means $\pm \mathrm{SD}$. ${ }^{* *}, \mathrm{P}<0.01 ;{ }^{* * *}, \mathrm{P}<0.001$; ns, not significant. P-values were obtained using Kruskal-Wallis tests plus Dunn's multiple comparison tests in A and B.

function by inhibiting the function of a $5 \mathrm{GABA} \mathrm{A}_{\mathrm{A}}$ $[13,15-17]$. As the expression of a5GABA decreases with age, we wondered whether the drug might either lose its effect or become more efficient in old mice. We thus gave young and old mice an intraperitoneal injection of 0.7 $\mathrm{mg} / \mathrm{kg} \mathrm{L}-655,708$ or vehicle (DMSO) 30 minutes before isoflurane anesthesia (1.33\% for 1 hour). FCTs were conducted 24 hours later. Consistent with previous studies $[13,16]$, the cognitive function of young mice was improved by L-655,708, as evidenced by their increased freezing times when pre-treated with $L-655,708$ (Fig 4, Supplemental Table). L-655,708 injections however did not significantly reduce the isoflurane-induced memory deficits in old mice (Fig 4, Supplemental Table). Collectively, we observed that, though L-655,708 can prevent isoflurane-induced cognitive decline in young mice, it is not effective in old mice. 


\section{Discussion}

In the present study, we evaluated the efficacy of $L-655,708$, an inverse agonist of ${\text { a } 5 G A B A_{A^{\prime}}}$ in preventing anesthesia-related memory deficits in old mice. We observed that old mice exhibited memory impairment and found that the expression of hippocampal a5GABA was significantly lower in old mice than in young mice. Furthermore, a 1-hour inhalation of isoflurane caused memory deficits in both young and old mice to a comparable level. L-655,708 alleviated the anesthesia-induced cognitive decline in young mice, but not in old mice. Our study suggests that L-655,708 is not as effective for the prevention of anesthesiainduced cognitive impairment in old mice as it is in young mice.

Age-related cognitive decline is associated with changes of multiple cells, pathways, and molecules [23]. The hippocampus is one of the regions that are more susceptible to aging [24]. We also observed that the hippocampi-dependent memory rather than the hippocampi-independent memory was worse in the old mice than in young mice. Hippocampal CA3 cells in aged rats have abnormally high firing rates compared to the same cells in young rats [25], indicating the hyperactivated state of the hippocampus in aged rats. Correspondingly, it was found that inhibiting the excess activity of CA3 neurons improves cognition in old rats [26]. More importantly, increased hippocampal activation has also been observed in aged humans using functional MRI [27]. These studies implicate that the over-activation, but not the inhibition, of the hippocampus contributes to age-related cognitive impairment. High hippocampal expression of the subunits NR1 and NR2B of $\mathrm{N}$-methyl-D-aspartate receptor, the receptor for excitatory neurotransmitter glutamate, is associated with poorer memory in aged mice [28]. We also find that the protein expression of NR2B in the hippocampus of old mice is higher than that in the young mice under normal conditions (data not shown). Impairment of the GABAergic system, the primary inhibitory system in the central nervous system, is observed in the hippocampus of aged animals, and is closely related to neurocognitive aging
$[29,30]$. Studies have suggested that the loss of GABAergic interneurons [31, 32], the reduction in GABA receptors [33], the impairment of GABAergic synaptic contacts [34], and the decline in GABA inhibitory postsynaptic currents [35] all contribute to the deterioration of GABAergic function during aging. In our study, old mice exhibited impaired cognition and lower expression of hippocampal a5GABA Another study also reported a reduction in mRNA levels of a5GABA $A_{A}$ in the hippocampus of memory-impaired aged rats [36]. Hence, together with other research, the current findings support the notion that age-related cognitive decline correlates with hippocampal overactivation, which might be caused by the excitatory/inhibitory imbalance.

Studies that use genetically modulated (knockout or point-mutated) mice have suggested that a $5 \mathrm{GABA}_{\mathrm{A}}$ plays a critical role in memory and learning [8-10]. Plenty of research aimed to use NAMs of a5GABA $A_{A}$ receptors to prevent or treat cognitive decline. Inverse agonists of a $5 \mathrm{GABA}_{\mathrm{A}^{\prime}}$ including $\mathrm{L}-655,708$, R04938581, and a5IA, were reported to enhance cognition without inducing proconvulsant effects in rats [15, 37-39]; the age of the animals in these studies was however not specifically mentioned. In accordance with the notion that age-related memory decline is accompanied by a reduction in a5GABA $A^{\prime}$ one study showed that TB21007, another NAM of $a_{5} G_{B B A}$, can improve memory performance in young rats, but not in memory-impaired aged rats [40]. More importantly, Compound 6 and Compound 44, two positive allosteric

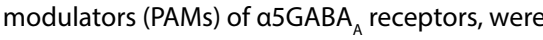
found to be effective in improving cognition in memory-impaired old rats, but not in young rats [40]. As for research in human, a5IA has been found to block alcohol-related learning impairment in healthy young (25-year-old) volunteers [41], while it did not improve performance on a paired-associated learning task (indeed, a dose of $4 \mathrm{mg}$ worsened the performance) in volunteers aged 72 years on average [42]. Age-related memory decline may thus be caused by a decrease, but not by an increase in a $5 \mathrm{GABA}_{A}$ levels. The different effects of L-655,708 in young and old mice observed in our study also indicate the complex role of
a5GABA in aging. Thus, the use of compounds that regulate $a 5 G A B A_{A}$ receptors to improve cognition in old age needs to be studied further.

The activation of $\mathrm{a} 5 \mathrm{GABA} \mathrm{A}_{\mathrm{A}}$ mediates, at least in part, the memory blockade during anesthesia [11, 12, 43]. More importantly, while the synaptic inhibition is transient, tonic inhibition mediated by a $5 \mathrm{GABA}_{\mathrm{A}}$ can persist for weeks after anesthesia [13]. Thus, the persistent increase function of a5GABA $A_{A}$ also accounts for persistent memory deficits after general anesthesia [13]. Many studies focus on the use of NAMs of a5GABA $A_{A}$ receptors to prevent or to treat cognitive decline caused by anesthesia. Assessed by FCTs and novel object recognition tests, it has been found that preinjection of L-655,708 can prevent isofluraneand etomidate-induced memory decline in mice $[13,16,17]$. The age of the animals used in these studies was 8 to 16 weeks $[16,17]$, or, in one case, not specifically mentioned [13]. We also found that L-655,708 markedly prevents isoflurane-induced cognitive deficits in 3- to 5 -month-old mice, while the effect was not obvious in 18- to 20-month-old mice. Several reasons may explain the failure of $L-655,708$ in preventing anesthesia-induced memory deficits in old mice.

First, as the NAMs of $a_{5 G A B A}$ cannot significantly improve cognitive decline in aged animals with low a5GABA $A_{A}$ expression [40], the expression levels of a5GABA $A_{A}$ may be critical for the efficacy of its NAMs. We found that the expression of a5GABA $A_{A}$ was not upregulated by a 1-hour isoflurane inhalation and that the old mice expressed less hippocampal a5GABA . Therefore, we speculate that the relatively low level of ${ }^{5} 5 \mathrm{GABA}_{\mathrm{A}}$ even after anesthesia contributed to the ineffectiveness of $L-655,708$.

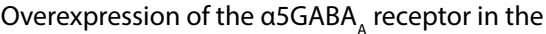
hippocampus of old mice may help to confirm the role of a5GABA in the reduced drug effect in old mice. More precise experiments, such as intracerebral injection of a $5 \mathrm{GABA}_{\mathrm{A}}$-expressing lentivirus, are needed for further study.

The second reason may be different responses of old and young brains to anesthesia. There is less new cell proliferation in the hippocampus of aged animals [44, 45], and isoflurane markedly decreased the number of 
mature neurons in aged, but not young rats [46]. Furthermore, isoflurane induced hippocampal inflammation in aged mice but not young mice [47]. These studies suggest that the alterations caused by anesthetics are amplified in aged brains. Neuroinflammation [48], malfunction of neural stem cells [49], and the activation/ inhibition of ligand-gated ion channels $[13,50,51]$ all contribute to neurocognitive impairment after anesthesia. Because of the high susceptibility of the aged to anesthetics, and because various pathways are regulated by anesthetics, we think that there are more changes induced by isoflurane in aged mice; only regulating the $a 5 G A B A_{A}$ pathway may therefore be insufficient to improve cognition.

Third, the activation of other non-a5GABA receptors by L-655,708 may also have affected its efficacy in our study. The affinity of L-655,708 to the a5 subunit of GABA receptors is 107,61 , and 54 times that of the $\alpha 1, \alpha 2$, and $a 3$ subunits, respectively [52]. It has been shown that a higher dose of inverse agonist may increase the activity of $G A B A_{A}$ receptors, because of the agonist-like effects on non-a $5 G A B A_{A}$ receptors [53]. One study found that L-655,708 at 0.35 $\mathrm{mg} / \mathrm{kg}$ can fully reverse, while a high dose of $\mathrm{L}-655,708(0.7 \mathrm{mg} / \mathrm{kg})$ failed to reverse the memory deficits caused by isoflurane [17], suggesting the excess of L-655,708 might lead to its ineffectiveness. A human study reported that, the maximal tolerated dose of MRK-016, another inverse agonist of $\mathrm{a}_{5 \mathrm{GABA}}$, is $5 \mathrm{mg}$ in young subjects, while only $0.5 \mathrm{mg}$ in the elderly subjects [54], indicating the effective dose of a5GABA $A_{A}$ inverse agonist is much lower in the elderly than in the young one. In the present study, we found that $0.7 \mathrm{mg} / \mathrm{kg}$ of L-655,708 can prevent isoflurane-induced memory decline in young mice, but not in the relatively little a5GABA $A_{A}$-expressing old mice. Together with previous studies, we speculate that the excess of L-655,708 may activate non-a5GABA receptors, thus leading to the inefficacy of $\mathrm{L}-655,708$ in the old subjects. Other doses of L-655,708 were not tested in the present study, so it is still unknown whether a lower dose of $\mathrm{L}-655,708$ is effective in old mice.

\section{Conclusions}

We observed that hippocampal a5GABA expression is lower in old mice than in young mice. Consistent with previous studies, we showed that pretreatment with L-655,708, the inverse agonist of $\mathrm{a}_{5 \mathrm{GABA}}$, prevented isoflurane-induced cognitive decline in young mice. L-655,708 however did not prevent anesthesia-related memory deficits in old mice. The age-related decrease in a5GABA in the hippocampus, the vulnerability of the aged brain to anesthetics, and the non-specific GABA activation by $L-655,708$ might contribute to the difference in the effect of L-655,708 on the prevention of isoflurane-induced memory deficits between young and old mice. It is important to note that the involvement of a5GABA $A_{A}$ in anesthesia-induced memory decline in old animals as well as the precise mechanism underlying the failure of L-655,708 to improve cognition in old mice remain to be elucidated. As a number of NAMs of a5GABA $A_{A}$ are under development for psychiatric and neurological diseases, special attention should be paid to the different effects in elderly and young patients.

\section{Abbreviations}

POCD, postoperative cognitive dysfunction; GABA, $y$-aminobutyric acid subtype $A ; F C T$, fear-conditioning test; NAM, negative allosteric modulator; DMSO, dimethyl sulfoxide; ANOVA, analysis of variance; PAM, positive allosteric modulator

References

[1] Newman S, Stygall J, Hirani S, Shaefi S, and Maze M. Postoperative cognitive dysfunction after noncardiac surgery: A systematic review. Anesthesiology. 2007;106:572-90.

[2] Monk TG, Weldon BC, Garvan CW, Dede DE, van der Aa MT, Heilman $\mathrm{KM}$, et al. Predictors of cognitive dysfunction after major noncardiac surgery. Anesthesiology. 2008;108:18-30.

[3] Paredes S, Cortinez L, Contreras V, and Silbert B. Post-operative cognitive dysfunction at 3 months in adults after non-cardiac surgery: A qualitative systematic review. Acta Anaesthesiol Scand. 2016;60:1043-58.

[4] Steinmetz J, Christensen KB, Lund T, Lohse N, Rasmussen LS, and Group I. Long-term consequences of postoperative cognitive dysfunction. Anesthesiology. 2009;110:548-55.

[5] Hemmings HC, Jr., Akabas MH, Goldstein PA, Trudell JR, Orser BA, and Harrison NL. Emerging molecular mechanisms of general anesthetic action. Trends Pharmacol Sci. 2005;26:503-10.

[6] Bonin RP, and Orser BA. Gaba(a) receptor subtypes underlying general anesthesia. Pharmacol Biochem Behav. 2008;90:105-12.

[7] Caraiscos VB, Elliott EM, You-Ten KE, Cheng VY, Belelli D, Newell JG, et al. Tonic inhibition in mouse hippocampal ca1 pyramidal neurons is mediated by alpha5 subunit-containing gamma-aminobutyric acid type a receptors. Proc Natl Acad Sci U S A. 2004;101:3662-7.

[8] Yee BK, Hauser J, Dolgov VV, Keist R, Mohler H, Rudolph U, et al. Gaba receptors containing the alpha5 subunit mediate the trace effect in aversive and appetitive conditioning and extinction of conditioned fear. Eur J Neurosci. 2004;20:1928-36.

[9] Collinson N, Kuenzi FM, Jarolimek W, Maubach KA, Cothliff R, Sur C, et al. Enhanced learning and memory and altered gabaergic synaptic transmission in mice lacking the alpha 5 subunit of the gabaa receptor. J Neurosci. 2002;22:5572-80.

[10] Crestani F, Keist R, Fritschy JM, Benke D, Vogt K, Prut L, et al. Trace fear conditioning involves hippocampal alpha5 gaba(a) receptors. Proc Natl Acad Sci U S A. 2002;99:8980-5.

[11] Cheng VY, Martin LJ, Elliott EM, Kim JH, Mount HT, Taverna FA, et al. Alpha5gabaa receptors mediate the amnestic but not sedativehypnotic effects of the general anesthetic etomidate. J Neurosci. 2006;26:3713-20.

[12] Martin LJ, Oh GH, and Orser BA. Etomidate targets alpha5 gammaaminobutyric acid subtype a receptors to regulate synaptic plasticity and memory blockade. Anesthesiology. 2009;111:1025-35. 
[13] Zurek AA, Yu J, Wang DS, Haffey SC, Bridgwater EM, Penna A, et al. Sustained increase in alpha5gabaa receptor function impairs memory after anesthesia. J Clin Invest. 2014;124:5437-41.

[14] Lecker I, Yin Y, Wang DS, and Orser BA. Potentiation of gabaa receptor activity by volatile anaesthetics is reduced by alpha5gabaa receptorpreferring inverse agonists. Br J Anaesth. 2013;110 Suppl 1:i73-81.

[15] Atack JR, Bayley PJ, Seabrook GR, Wafford KA, McKernan RM, and Dawson GR. L-655,708 enhances cognition in rats but is not proconvulsant at a dose selective for alpha5-containing gabaa receptors. Neuropharmacology. 2006;51:1023-9.

[16] Saab BJ, Maclean AJ, Kanisek M, Zurek AA, Martin LJ, Roder JC, et al. Short-term memory impairment after isoflurane in mice is prevented by the alpha5 gamma-aminobutyric acid type a receptor inverse agonist I-655,708. Anesthesiology. 2010;113:1061-71.

[17] Zurek AA, Bridgwater EM, and Orser BA. Inhibition of alpha5 gammaaminobutyric acid type a receptors restores recognition memory after general anesthesia. Anesth Analg. 2012;114:845-55.

[18] Dutta S, and Sengupta P. Men and mice: Relating their ages. Life Sci. 2016;152:244-8

[19] Ding F, Zheng L, Liu M, Chen R, Leung LS, and Luo T. Ciproxifan, an h3 receptor antagonist, improves short-term recognition memory impaired by isoflurane anesthesia. J Anesth. 2016;30:684-90.

[20] Zhou S, Chen HZ, Wan YZ, Zhang QJ, Wei YS, Huang S, et al. Repression of p66shc expression by sirt1 contributes to the prevention of hyperglycemia-induced endothelial dysfunction. Circ Res. 2011;109:639-48.

[21] Satomoto $M$, Satoh $Y$, Terui K, Miyao H, Takishima K, Ito $M$, et al. Neonatal exposure to sevoflurane induces abnormal social behaviors and deficits in fear conditioning in mice. Anesthesiology. 2009;110:628-37.

[22] Stratmann G, Sall JW, Bell JS, Alvi RS, May L, Ku B, et al. Isoflurane does not affect brain cell death, hippocampal neurogenesis, or long-term neurocognitive outcome in aged rats. Anesthesiology. 2010;112:30515.

[23] Konar A, Singh P, and Thakur MK. Age-associated cognitive decline: Insights into molecular switches and recovery avenues. Aging Dis. 2016;7:121-9.

[24] Zeier Z, Madorsky I, Xu Y, Ogle WO, Notterpek L, and Foster TC. Gene expression in the hippocampus: Regionally specific effects of aging and caloric restriction. Mech Ageing Dev. 2011;132:8-19.

[25] Wilson IA, Ikonen S, Gallagher M, Eichenbaum H, and Tanila H. Ageassociated alterations of hippocampal place cells are subregion specific. J Neurosci. 2005;25:6877-86.

[26] Koh MT, Haberman RP, Foti S, McCown TJ, and Gallagher M. Treatment strategies targeting excess hippocampal activity benefit aged rats with cognitive impairment. Neuropsychopharmacology. 2010;35:1016-25.

[27] Ewers $M$, Sperling RA, Klunk WE, Weiner MW, and Hampel $H$. Neuroimaging markers for the prediction and early diagnosis of alzheimer's disease dementia. Trends Neurosci. 2011;34:430-42.

[28] Zhao X, Rosenke R, Kronemann D, Brim B, Das SR, Dunah AW, et al. The effects of aging on $n$-methyl-d-aspartate receptor subunits in the synaptic membrane and relationships to long-term spatial memory. Neuroscience. 2009;162:933-45.

[29] McQuail JA, Frazier CJ, and Bizon JL. Molecular aspects of agerelated cognitive decline: The role of gaba signaling. Trends Mol Med. 2015;21:450-60.

[30] Rozycka A, and Liguz-Lecznar M. The space where aging acts: Focus on the gabaergic synapse. Aging Cell. 2017;16:634-43.

[31] Stanley EM, Fadel JR, and Mott DD. Interneuron loss reduces dendritic inhibition and gaba release in hippocampus of aged rats. Neurobiol Aging. 2012;33:431 e1-13.

[32] Spiegel AM, Koh MT, Vogt NM, Rapp PR, and Gallagher M. Hilar interneuron vulnerability distinguishes aged rats with memory impairment. J Comp Neurol. 2013;521:3508-23.

[33] Hoekzema E, Rojas S, Herance R, Pareto D, Abad S, Jimenez X, et al. In vivo molecular imaging of the gaba/benzodiazepine receptor complex in the aged rat brain. Neurobiol Aging. 2012;33:1457-65.

[34] Majdi M, Ribeiro-da-Silva A, and Cuello AC. Cognitive impairment and transmitter-specific pre- and postsynaptic changes in the rat cerebral cortex during ageing. Eur J Neurosci. 2007;26:3583-96.

[35] Potier B, Jouvenceau A, Epelbaum J, and Dutar P. Age-related alterations of gabaergic input to ca1 pyramidal neurons and its control by nicotinic acetylcholine receptors in rat hippocampus. Neuroscience. 2006;142:187-201.

[36] Haberman RP, Colantuoni C, Stocker AM, Schmidt AC, Pedersen JT, and Gallagher M. Prominent hippocampal ca3 gene expression profile in neurocognitive aging. Neurobiol Aging. 2011;32:1678-92.

[37] Ballard TM, Knoflach F, Prinssen E, Borroni E, Vivian JA, Basile J, et al. Ro4938581, a novel cognitive enhancer acting at gabaa alpha5 subunit-containing receptors. Psychopharmacology (Berl). 2009;202:207-23.

[38] Collinson N, Atack JR, Laughton P, Dawson GR, and Stephens DN. An inverse agonist selective for alpha5 subunit-containing gabaa receptors improves encoding and recall but not consolidation in the morris water maze. Psychopharmacology (Berl). 2006;188:619-28.

[39] Dawson GR, Maubach KA, Collinson N, Cobain M, Everitt BJ, MacLeod $A M$, et al. An inverse agonist selective for alpha5 subunit-containing gabaa receptors enhances cognition. J Pharmacol Exp Ther. 2006;316:1335-45.

[40] Koh MT, Rosenzweig-Lipson S, and Gallagher M. Selective gaba(a) alpha5 positive allosteric modulators improve cognitive function in aged rats with memory impairment. Neuropharmacology. 2013;64:145-52.

[41] Nutt DJ, Besson M, Wilson SJ, Dawson GR, and Lingford-Hughes AR. Blockade of alcohol's amnestic activity in humans by an alpha5 subtype benzodiazepine receptor inverse agonist. Neuropharmacology. 2007;53:810-20.

[42] Atack JR. Preclinical and clinical pharmacology of the gabaa receptor alpha5 subtype-selective inverse agonist alpha5ia. Pharmacol Ther. 2010;125:11-26.

[43] Martin LJ, Zurek AA, MacDonald JF, Roder JC, Jackson MF, and Orser BA. Alpha5gabaa receptor activity sets the threshold for long-term potentiation and constrains hippocampus-dependent memory. J 
Neurosci. 2010;30:5269-82.

[44] Lazarov O, Mattson MP, Peterson DA, Pimplikar SW, and van Praag $\mathrm{H}$. When neurogenesis encounters aging and disease. Trends Neurosci. 2010;33:569-79.

[45] Erasso DM, Chaparro RE, Quiroga Del Rio CE, Karlnoski R, Camporesi EM, and Saporta S. Quantitative assessment of new cell proliferation in the dentate gyrus and learning after isoflurane or propofol anesthesia in young and aged rats. Brain Res. 2012;1441:38-46.

[46] Erasso DM, Camporesi EM, Mangar D, and Saporta S. Effects of isoflurane or propofol on postnatal hippocampal neurogenesis in young and aged rats. Brain Res. 2013;1530:1-12.

[47] Wang Z, Meng S, Cao L, Chen Y, Zuo Z, and Peng S. Critical role of nlrp3-caspase-1 pathway in age-dependent isoflurane-induced microglial inflammatory response and cognitive impairment. J Neuroinflammation. 2018;15:109.

[48] Liu Y, and Yin Y. Emerging roles of immune cells in postoperative cognitive dysfunction. Mediators Inflamm. 2018;2018:6215350.

[49] Stratmann G, Sall JW, May LD, Bell JS, Magnusson KR, Rau V, et al. Isoflurane differentially affects neurogenesis and longterm neurocognitive function in 60-day-old and 7-day-old rats. Anesthesiology. 2009;110:834-48.
[50] Piao MH, Liu Y, Wang YS, Qiu JP, and Feng CS. Volatile anesthetic isoflurane inhibits Itp induction of hippocampal ca1 neurons through alpha4beta2 nachr subtype-mediated mechanisms. Ann Fr Anesth Reanim. 2013;32:e135-41.

[51] Su D, Zhao Y, Wang B, Xu H, Li W, Chen J, et al. Isofluraneinduced spatial memory impairment in mice is prevented by the acetylcholinesterase inhibitor donepezil. PLoS One. 2011;6:e27632.

[52] Quirk K, Blurton P, Fletcher S, Leeson P, Tang F, Mellilo D, et al. [3h] $\mathrm{I}-655,708$, a novel ligand selective for the benzodiazepine site of gabaa receptors which contain the alpha 5 subunit. Neuropharmacology. 1996;35:1331-5.

[53] Savic MM, Huang S, Furtmuller R, Clayton T, Huck S, Obradovic DI, et al. Are gabaa receptors containing alpha 5 subunits contributing to the sedative properties of benzodiazepine site agonists? Neuropsychopharmacology. 2008;33:332-9.

[54] Atack JR, Maubach KA, Wafford KA, O'Connor D, Rodrigues AD, Evans DC, et al. In vitro and in vivo properties of 3-tert-butyl-7-(5methylisoxazol-3-yl)-2-(1-methyl-1h-1,2,4-triazol-5-ylmethoxy)pyrazolo[1,5-d]-[1,2,4]triazine (mrk-016), a gabaa receptor alpha5 subtype-selective inverse agonist. J Pharmacol Exp Ther. 2009;331:470-84. 